\title{
FEMINISMO E TERAPIA: A TERAPIA FEMINISTA DA FAMÍLIA - POR UMA PSICOLOGIA COMPROMETIDA ${ }^{1}$
}

\author{
Martha Giudice Narvaz* \\ Silvia Helena Koller**
}

\section{Resumo}

O objetivo deste trabalho é destacar a terapia feminista da família enquanto abordagem crítica no campo das psicoterapias e das terapias familiares. Inicialmente, descrevemos o feminismo enquanto campo político, teórico e epistemológico, bem como a incorporação do paradigma feminista ao campo das psicoterapias. Descrevemos também o surgimento da vertente feminista da terapia familiar e as principais críticas feministas às terapias familiares sistêmicas tradicionais. Ao final, destacamos a terapia feminista da família como uma prática comprometida com a crítica dos saberes hegemônicos instituídos sobre os papéis e lugares dos gêneros na trama do social.

Palavras-chave: terapia feminista, feminismo, terapia familiar, gênero, psicoterapias

\section{Abstract}

FEMINISM AND THERAPY: FEMINIST FAMILY THERAPY - FOR AN ENGAGED PSYCHOLOGY

This paper intends to point out feminist family therapy as a critical approach in the family therapy field. Initially, we describe feminism like a political, theoretical and epistemological

* Psicóloga e Terapeuta Familiar com especialização na área da violência doméstica pela Universidade de São Paulo (USP); Doutoranda em Psicologia do Desenvolvimento pela Universidade Federal do Rio Grande do Sul (UFRGS); Integrante do Centro de Estudos Psicológicos sobre Meninos e Meninas de Rua - CEP-RUA/UFRGS e da ONG Feminista Coletivo, Feminino Plural de Porto Alegre.

** Psicóloga; Doutora em Educação pela Pontifícia Universidade Católica do Rio Grande do Sul (PUCRS); Professora do Programa de Pós-Graduação em Psicologia do Desenvolvimento da Universidade Federal do Rio Grande do Sul (UFRGS); Coordenadora do Centro de Estudos Psicológicos sobre Meninos e Meninas de Rua - CEP-RUA/UFRGS. 
field, as well as the incorporation of feminist assumptions by psychotherapy. We also describe the emergence of feminist family therapy and the major feminist criticism against traditional systemic family therapy. At the end, we highlight feminist family therapy like an engaged practice that reviews traditional and hegemonic knowledge about gender roles and places in the general social scheme.

Keywords: feminist therapy, feminism, family therapy, gender, psychotherapy

"Trata-se sempre de liberar a vida lá onde ela é prisioneira".

(Deleuze \& Guatarri, 1997: 23)

\section{INTRODUÇÃO}

O objetivo deste trabalho é o de destacar a terapia feminista da família enquanto abordagem crítica no campo das psicoterapias e, em especial, das terapias familiares. $\mathrm{O}$ interesse pelo tema vem-se construindo no cotidiano de nossa prática enquanto psicólogas, pesquisadoras e terapeutas de famílias e de grupos de mulheres e de meninas vítimas de várias formas de violência, sobretudo de violência sexual. Também nossa inserção em inúmeros debates acadêmicos e políticos, bem como a assessoria na capacitação da rede de atendimento a vítimas de violência em várias cidades do país tem-nos revelado o despreparo da rede para a adequada acolhida das vítimas de violência. Temos encontrado, nesse sentido, discursos segundo os quais as mulheres e as meninas são percebidas como coniventes de seus agressores, sedutoras e provocadoras das violências que sofrem. Estes discursos (inscritos nas práticas de profissionais de diversas disciplinas, dentre elas, da psicologia), implícita e, por vezes, explicitamente, responsabilizavam as vítimas pelos abusos sofridos (Narvaz \& Koller, 2006a). Ao invés de constituírem-se em rede de proteção, de garantia de direitos e de promoção de saúde, tais instituições desempenhavam o papel de dispositivos de revitimização feminina. Uma vez que o apoio social é suporte necessário à superação das situaçōes de vulnerabilidade impetradas pela violência, é fundamental que exista uma rede de apoio competente e articulada para o acolhimento das vítimas (Narvaz \& Koller, 2006c). O que se percebe, no entanto, na realidade brasileira, é o despreparo das instituições para cumprirem com sua tarefa, seja por falta de recursos humanos, materiais e/ou pouca qualificação (Brino \& Willians, 2003; Negrão, 2004; Oliveira, 2004; Strey, Werba \& Nora, 2004). 
Comprometida com a denúncia da violência e dos dispositivos mantenedores do gênero feminino em situações de vulnerabilidade e de subordinação, temos investigado os discursos reguladores do feminino enquanto categoria social. A análise destes discursos (Narvaz, 2005) revelou que diversas formas de violência contra o gênero feminino são engendradas pela formação discursiva patriarcal, que regula e normatiza os lugares e as relações de gênero no social. A violência contra as mulheres e contra as meninas revela-se, assim, profundamente implicada nas relações de poder constitutivas das relações de gênero. Estes discursos normativos são produzidos e veiculados no senso comum, nos saberes científicos e nas diversas pedagogias culturais, destacando-se aqui o papel da escola e da mídia (Louro, 1999, 2003). Poder e saber, entrelaçados, constituem discursos que, através de saberes e práticas que se outorgam o estatuto de verdade, regulam formas morais de comportamento aos sujeitos. Uma vez que esta complexa rede de tecnologias e de sistemas disciplinares, pela qual o poder opera na regulação dos gêneros, inscreve-se nas disciplinas normalizantes da medicina, da educação e da psicologia (Foucault, 1969, 1976/1995, 1975/2002), há que se analisar os discursos que circulam nas práticas terapêuticas, entre elas, nas terapias familiares. Este trabalho propõe-se, assim, a problematizar teorias e práticas que nos constituem tão profundamente que nem as percebemos mais como aprendidas, tal como nos ensina Foucault (1969/1988); tarefas teórico-epistemológicas e políticas implicadas no fazer comprometido das terapias feministas.

\section{FEMINISMO ENQUANTO CAMPO POLítico, TEÓRICO E EPISTEMOLÓgICO}

A tradição científica positivista, com seus ideais de racionalidade, objetividade e neutralidade, afastaram a emoção, a subjetividade e as lutas políticas do critério de cientificidade. Assumir uma posição política parece estar na contramão do discurso científico e das práticas terapêuticas. Entretanto, ao dizerem-se "apolíticas", diversas práticas colocam-se a serviço da dominação patriarcal (Fonseca, 1997).

Sabemos que a expressão "feminista" é marcada por confusões e preconceitos (Jones, 1994). O feminismo, que surge do movimento de luta das mulheres por direitos civis e políticos, é também um campo teórico-epistemológico extremamente fértil em suas problematizações. Ousando criticar a cultura androcêntrica ocidental, produziu desafios poderosos a concepções hegemônicas da natureza humana, da razão, da racionalidade científica e do sujeito. Campo denso de reflexões e de debates, o feminismo vem problematizando-se e transformando-se desde as doutrinas do feminismo original. Ainda que um discurso heterogêneo e de 
várias tendências, os vários feminismos têm, entretanto, uma base comum: reconhecem que homens e mulheres têm experiências diferentes e reivindicam que pessoas diferentes sejam tratadas não como iguais, mas como equivalentes (Narvaz \& Koller, 2006d).

As feministas desafiaram as formas de produção do conhecimento e indagaram que visão de mundo o conhecimento representa e a que interesses está servindo, originando, na intersecção das lutas políticas com a academia, o campo das epistemologias feministas. A epistemologia feminista não é, entretanto, um domínio estável. Ao contrário, representa um espaço de contestação e de dúvida acerca do que é considerado "conhecimento", quem o define e como se obtém, a partir de diferentes posicionamentos epistemológicos feministas (Harding, 1986, 1993). Mais apropriado seria falar em epistemologias e em metodologias, no plural, uma vez que não há uma só forma de fazer ciência a partir das lentes oferecidas pelo feminismo e pelos estudos de gênero. De toda forma, a epistemologia feminista abre-se para um campo essencialmente multidisciplinar, onde a perspectiva da pluralidade é imprescindível. A ciência, nessa perspectiva, tem gênero, havendo diferentes maneiras de se fazer ciência. Homens e mulheres, em diferentes épocas, em diferentes lugares e sob diferentes orientações teórico-epistemológicas, podem produzir conhecimento de formas diferenciadas. Entretanto, a objetividade foi equiparada à masculinidade, o que conduziu a presumir que, para ser objetivo, requer-se distanciamento e separação entre emocionalidade e intelectualidade. A imparcialidade, a partir da perspectiva feminista da produção do conhecimento, não é possível, sequer desejável, especialmente uma vez que se encontra comprometida com a mudança social. A epistemologia feminista entende que o conhecimento é sempre situado, posicionando-se contra a objetividade e a neutralidade características da ciência positivista androcêntrica e resgatando o papel da emoção, do corpo e da experiência na produção do conhecimento científico (Eichler, 1988; Harding, 1986; Jaggar, 1997; Keller, 1985). As feministas denunciam que a experiência masculina tem sido privilegiada ao longo da história, enquanto a feminina, negligenciada e desvalorizada. Elas demonstraram, ainda, que o poder foi (e ainda é) predominantemente masculino, cujo objetivo original foi a dominação das mulheres, especialmente de seus corpos (Diamond \& Quinby, 1988; Millet, 1970; Pateman, 1993).

O feminismo enquanto crítica da modernidade (Benhabib \& Cornell, 1987) não tem, entretanto, sido reconhecido ou legitimado pela comunidade científica e acadêmica, dada sua estreita relação com a militância feminista. $\mathrm{O}$ preconceito e a marginalização imputados aos paradigmas feministas e aos estudos de gênero têm sido apontados por diversas pesquisadoras, o que se constitui em importante 
obstáculo à sua legitimação (Adelman, 2003; Bordo, 2001; Costa, 1994). Tal marginalização parece estar associada à relação do surgimento e da institucionalização deste campo de estudos com os movimentos sociais, sobretudo em sua estreita vinculação com os partidos de esquerda e com os movimentos de mulheres. No Brasil, o processo de formação do movimento feminista ocorreu, em grande parte, no contexto da história dos partidos de esquerda na luta contra a ditadura militar. Tributários das ações conduzidas pelo movimento de mulheres a partir dos anos 60, os movimentos feministas envolveram pesquisadoras, acadêmicas e militantes que atuavam dentro de um mesmo projeto político, qual seja, o de confrontar e de contestar as discriminaçóes e as relações de poder existentes na sociedade (Costa \& Schmidt, 2004; Maluf, 2004; Toneli, 2003). Cabe destacar que os movimentos de mulheres eram movimentos de lutas populares protagonizados por mulheres que defendiam causas sociais amplas ditadas pela agenda da esquerda. Já os movimentos feministas eram movimentos que buscavam uma agenda autônoma e específica, voltada para as questōes da opressão e das desigualdades entre homens e mulheres. Os movimentos feministas distinguiram-se dos movimentos de mulheres ao denunciarem a negligência às questôes específicas das mulheres e as discriminaçóes sexistas e hierárquicas vividas pelas mulheres dentro das organizações de esquerda, historicamente masculinas e patriarcais (Blay, 2001; Colling, 1997; Ferreira, 1996; Schmidt, 2004).

Neste contexto, acadêmicas e militantes buscavam denunciar a opressão vivida pelas mulheres, sobretudo na família e no mercado de trabalho. O campo de estudos de gênero, inicialmente voltado para os estudos sobre as mulheres, foi-se consolidando, no Brasil, no final dos anos 70, concomitantemente ao processo de redemocratização política, ao fortalecimento dos movimentos sociais e do movimento feminista no país (Costa, 1994; Farah, 2004). Nos anos 80, a produção acadêmica sobre o tema cresceu e diversificou-se, deixando de concentrar-se na Sociologia para incluir a Antropologia, a História, a Literatura, a Psicanálise, o Direito, a Saúde, a Psicologia, a Política, a Educação, a Comunicação, as Artes, a Geografia e a Economia. Começaram a surgir, nas Universidades, os núcleos de estudos e pesquisas sobre a mulher, sendo que as publicaçôes e teses envolvendo tal temática aumentaram consideravelmente nesta época. No final da década de 90, as principais associações de cientistas do país, entre elas a Associação Brasileira de Psicologia Social (ABRAPSO), contavam com grupos de trabalhos especializados na temática de gênero. Apesar da crescente consolidação deste campo de estudos no Brasil, sua inserção no espaço acadêmico sempre foi marginal, ocorrendo predominantemente na pesquisa, em detrimento do ensino. A maioria dos cursos foi (e ainda é) oferecida na pós-graduação, onde há maior flexibilidade curricular, 
sendo que, na graduação, são oferecidas apenas disciplinas optativas, não havendo cursos regulares sobre relações de gênero (Blay, 2001; Costa, 1994; Costa \& Schmidt, 2004; Schmidt, 2004). No campo da terapia familiar, verifica-se semelhante cenário: nos cursos de formação e de especialização em psicoterapia familiar no Brasil, é quase inexistente a discussão dos aspectos de gênero nos currículos. Uma análise dos Anais dos Congressos Brasileiros de Terapia Familiar dos últimos anos igualmente aponta o reduzido número de trabalhos apresentados tendo como temática principal as questões de gênero e/ou os paradigmas feministas das terapias familiares.

\section{As TERAPIAS FEMINISTAS}

Embora com resistências, a crítica feminista aos paradigmas positivistas da ciência adentrou a academia, a pesquisa e a clínica. Na psicologia, em especial a partir dos anos 70, vemos o surgimento da psicologia feminista e, a partir daí, as terapias feministas, que emergiram, sobretudo, dos estudos e trabalhos com grupos de mulheres (Nogueira, 2001). Dentre as abordagens terapêuticas feministas, encontra-se a terapia feminista da família, uma vertente da terapia familiar. Desde o surgimento da terapia familiar, houve uma diversidade de pressupostos teóricos que fundamentaram diferentes práticas. Conforme Perelberg (1994), a terapia de família surgiu na Europa, nos anos 60, com o movimento da antipsiquiatria e, nos anos 70, com o pensamento sistêmico, nos Estados Unidos. Na Inglaterra, desenvolveu-se a terapia familiar de base psicanalítica (Eiguer, 1998), que deslocou o estudo da "psique ao sistema” (Neill \& Kniskern, 1990). Na Itália, têm destaque duas escolas, representadas pelo grupo de Andolfi (Andolfi \& Angelo, 1989) e pela escola de Milão (Boscolo, Cecchin, Hoffman \& Penn, 1993). Nos Estados Unidos, estrutura-se o campo da terapia familiar sistêmica de base cibernética (Vasconcelos, 1995), tendo na escola estrutural de Minuchin (1981) uma das principais representantes. Na escola estrutural (Minuchin, 1981), a família é concebida como um sistema orgânico regido pelas leis da circularidade e da complementaridade. O objetivo dos sistemas é o de buscar a homeostase. $\mathrm{O}$ terapeuta é visto como alguém que deve ter poder sobre o sistema terapêutico e deve auxiliar a família a reestruturar-se em busca da homeostase. Os problemas familiares são atribuídos à falta de clareza na delimitação dos papéis e à falta de hierarquia entre os membros da família. Famílias com problemas são famílias disfuncionais, cabendo ao terapeuta auxiliá-las a restabeleceram as hierarquias e a delimitarem seus papéis a fim de tornarem-se novamente funcionais. As escolas italianas (Andolfi \& Angelo, 1989; Boscolo e cols., 1993) não compartilhavam 
dos pressupostos da escola sistêmica estrutural e nem da escola psicanalítica. As escolas italianas estimulavam a irreverência, o humor e as conexões relacionais, tanto na família, na terapia, quanto na formação dos terapeutas familiares.

Algumas correntes sistêmicas (Vasconcelos, 1995), influenciadas pelo pensamento pós-moderno, incorporam os paradigmas construcionistas. Terapeutas familiares filiados a diferentes escolas, em diversos lugares do mundo, revisam seus pressupostos e introduzem em suas formulaçôes conceitos como recursividade, entropia e reflexividade. Concebem a família como um sistema aberto em permanente transformação. Surgem, então, novas linhas teóricas e terapêuticas que refutam os pressupostos das abordagens sistêmicas cibernéticas tradicionais, cujas bases assentam-se nas teorias funcionalistas, representantes da primeira geração das terapias sistêmicas. Outras abordagens terapêuticas estruturam-se nesta nova fase da terapia familiar, tais como, por exemplo, o construcionismo social (Schnitman, 1996), a abordagem reflexiva (Andersen, 1991) e a terapia narrativa (Penn, 1988). Estas escolas valorizam a intersubjetividade, as narrativas circulares e a reflexividade no sistema terapêutico. $\mathrm{O}$ terapeuta faz parte do sistema e não tem uma posição marcada de poder na terapia. São as famílias que devem definir seus objetivos, sendo encorajadas a explorarem visões alternativas sobre suas dificuldades e a resgatarem suas competências na resolução destas dificuldades. Os problemas familiares não são vistos como disfunções, mas como narrativas ou descrições rígidas e estáticas que a família constrói sobre suas relações. O papel do terapeuta é auxiliar a família a ampliar tais descrições através de novas narrativas que são co-construídas no sistema terapêutico.

Terapeutas familiares originalmente filiadas aos grupos originais sistêmicos, tanto dos Estados Unidos quanto da Europa, descontentes com a negligência dos aspectos de gênero e com o androcentrismo da terapia familiar, realizaram conferências e formaram grupos de discussão. Estas terapeutas, oriundas predominantemente das abordagens construcionista, reflexiva e narrativa, que destacam a intersubjetividade e a dialogicidade na construção do sistema terapêutico, organizaram uma conferência sobre feminismo e terapia familiar, em 1982, em Londres (Perelberg, 1994; Urry, 1994). Esta conferência foi um dos marcos da fundação da terapia feminista da família, que surgiu, então, como crítica à abordagem tradicional das terapias sistêmicas, androcêntricas e funcionalistas. Algumas críticas feministas às terapias sistêmicas tradicionais referem-se a que: 1) na medida em que as abordagens sistêmicas tradicionais concebem a família como um todo orgânico em busca de homeostase, não consideram as diferenças de poder dentro da família; 2) os pressupostos da circularidade e complementaridade a partir dos quais funciona a família desconsideram as diferenças de poder no sistema famili- 
ar. A terapia feminista entende que a opressão ocorre de forma linearmente causal, não se podendo atribuir igual responsabilidade a pessoas que não têm o mesmo acesso ao poder dentro de um sistema. Os pressupostos da circularidade e da complementaridade deram margem a concepçôes tais como o papel igualmente participante das vítimas nas situaçôes de violência familiar; 3) negligenciando os aspectos de gênero na família, as terapias sistêmicas não problematizam os papéis familiares, mantendo, assim, as definições estáticas, binárias e rígidas sobre estes papéis, o que contribui com a manutenção da ordem patriarcal; 4) ao valorizarem o poder, as hierarquias e a busca de autonomia do indivíduo dentro da família, as terapias sistêmicas pautam-se em valores androcêntricos. Ficam desvalorizadas outras formas de conexão relacional predominantemente desenvolvidas pelas mulheres, tais como a busca da intimidade e a valorização do cuidado na família. Além disso, são idealizados valores tais como autonomia e independência, em detrimento do pertencimento e da intimidade; 5) as terapias tradicionais idealizam a função paterna, figura de poder e autoridade no sistema familiar, e culpabilizam as mães, sem problematizar as posiçôes de gênero tal qual são construídas na sociedade e na família; 6) na medida em que as terapias sistêmicas não questionam a instituição familiar tal como está construída em nossa sociedade, elas contribuem para a manutenção das desigualdades de gênero e da opressão feminina; e, 7) ao desconsiderar as questôes de gênero na formação e na supervisão, as terapias tradicionais deixam de considerar as especificidades vivenciadas pelos/as terapeutas, como se terapeutas não tivessem gênero e, com isso, possíveis implícitos a permearem suas práticas (Burck \& Daniel, 1994; Goldner, 1985, 1988; Hare-Mustin, 1987; Ravazzola, 1997, 1999). Cabe destacar que a terapia feminista da família não se propõe a criar um novo modelo de terapia familiar. Trata-se, isto sim, de incluir a questão do gênero e das diferenças de poder no sistema terapêutico como fundamentais à prática da terapia de família, quer nos seus aspectos teóricos, clínicos ou de formação, para, com isso, desvelar e desconstruir os implícitos sexistas que aí se apresentem (Rampage \& Avis, 1998).

A terapia feminista da família é uma prática terapêutica comprometida com a mudança social e com o empoderamento das mulheres na medida em que se opõe à normatização patriarcal hegemônica na sociedade, sobretudo na definição tradicional e estática de papéis e relaçôes familiares baseadas em estereótipos sexistas. Ao substituir o primado dos construtos intrapsíquicos pelos fatores contextuais e relacionais, as teorias sistêmicas, desde seu surgimento, re-localizam a gênese das dificuldades individuais nos processos e relações intersubjetivas. Neste cenário, as terapias feministas destacam as relaçóes de poder estruturantes das relações de gênero constitutivas das relações familiares e sociais. Ao invés de centrar sua atu- 
ação na redução da sintomatologia decorrente de processos de desajustamento individual, intervençōes terapêuticas sistêmicas e, em especial, as terapias feministas buscam auxiliar, no caso das mulheres, principais vítimas de diversas formas de discriminação e opressão, a identificação de suas capacidades e de suas competências a fim de esboçarem estratégias de resistência diante das violências sofridas. Orientando-as na busca dos recursos comunitários e legais disponíveis acerca de seus direitos, a terapia feminista da família envolve-se ativamente com o empoderamento dos grupos oprimidos, sobretudo das mulheres, cujas subjetividades ainda são marcadas por diversas formas de discriminação e violência. Articulam-se, assim, terapia e política na terapia feminista da família, uma prática comprometida com a crítica da sociedade patriarcal e com a mudança social na busca de relaçôes mais justas e igualitárias (Narvaz \& Koller, 2006d).

Enquanto muitas práticas terapêuticas tradicionais pretendem-se apolíticas, as terapias feministas assumem um compromisso marcadamente político com a mudança social, sobretudo no que concerne às questôes de gênero e de papéis sociais e sexuais atribuídos a homens e a mulheres no contexto familiar; enquanto algumas terapias tradicionais recorrem a construtos intrapsíquicos para compreender o sofrimento psíquico, as terapias feministas focalizam os fatores contextuais, em especial as desigualdades e a opressão patriarcal, como origem das dificuldades individuais e familiares; enquanto algumas terapias tradicionais buscam o ajustamento e a normatização e normalização dos indivíduos e das famílias aos papéis tradicionalmente prescritos, as terapias feministas confrontam esses papéis e essas normas; enquanto as terapias tradicionais estabelecem relações de poder-saber marcadamente desiguais com os/as clientes, as terapias feministas validam os saberes individuais e as experiências singulares dos indivíduos e das famílias, reduzindo o mais possível as diferenças de poder-saber envolvidas na relação terapêutica (Neves \& Nogueira, 2003).

A terapia feminista da família tem, ainda, problematizado as concepções tradicionais de família. A concepção de família aparece, ainda na atualidade, tanto nos discursos científicos quanto sociais, como uma única e específica forma de organização, ou seja, da família conjugal monogâmica, patriarcal, urbana e burguesa. Essa forma de organização é percebida como o modelo "normal" de família no imaginário social, naturalizada e legitimada como modelo monolítico e hegemônico de organização familiar. As demais configurações familiares são desqualificadas ou não reconhecidas como formas legítimas de "ser família", causando sofrimento aos sujeitos que vivem em configurações alternativas ao modelo normativo (Narvaz \& Koller, 2005, 2006b). A competência das famílias não depende de sua estrutura ou de sua configuração, mas da qualidade das relações 
estabelecidas entre seus membros (Costa, Penso \& Féres-Carneiro, 1992). Entretanto, as famílias que não são organizadas de forma nuclear são ditas "desestruturadas". Estas configurações ditas "alternativas" ao modelo normativo de família são, em geral, invisibilizadas e negligenciadas no campo da terapia familiar (Goodrich, Rampage, Ellman, \& Halstead, 1990). São, muitas vezes, consideradas problemáticas e disfuncionais simplesmente pelo fato de não corresponderem à estrutura normativa de família prescrita pela sociedade patriarcal, conservadora, burguesa e heterossexista. Muitas vezes, homens e mulheres, mesmo vivendo relações conjugais empobrecidas, permanecem em relações insatisfatórias, quando não violentas e abusivas, capturados pelos discursos científico e social de que famílias divorciadas são famílias "desestruturadas", discursos aos quais devemos estar atentos, sob pena de serem reproduzidos (Narvaz \& Koller, 2006b).

Sistemas terapêuticos tradicionais e conservadores, baseados em crenças e preconceitos acerca do ideal normativo de família nuclear, "inventam" disfunções e problemas, gerando sofrimento e culpa nos sujeitos que vivem configuraçóes familiares alternativas. Em nossa experiência clínica e de pesquisa com famílias monoparentais, adotivas, reconstituídas, com casais homossexuais e com famílias que vivem na pobreza (ditas "multiproblemáticas"), entre outras, percebemos que a forma e a qualidade das relações familiares não está diretamente associada à estrutura da configuração familiar vivida, mas, isto sim, às narrativas que tais famílias constroem sobre elas mesmas, quer sejam de desqualificação ou de valorização de suas capacidades, ao que contribui o sistema terapêutico com suas teorias e crenças (Narvaz \& Koller, 2005).

\section{CONSIDERAÇÕES FINAIS}

Consoante com as abordagens feministas, que advogam a ligação do fazer acadêmico com as práticas e lutas sociais (Fonseca, 1997; Neves \& Nogueira, 2003), este texto buscou destacar a proposta crítica engendrada pela terapia feminista da família. Ainda que tais proposiçōes críticas circulem nos discursos científicos desde a década de 80 do século XX (Canevacci, 1987; Figueira, 1986), tais discursos não parecem ter, ainda, estatuto de legitimidade plenamente reconhecido pela comunidade científica e acadêmica, o que se revela na análise dos currículos programáticos dos cursos de formação em terapia familiar e dos Anais dos Congressos Brasileiros de Terapia Familiar.

A ciência, às vezes, parece estar a serviço da dominação e da domesticação social, quando o seu discurso é utilizado como instrumento de legitimação e de 
naturalização das desigualdades e das subordinações, quer sejam de gênero, de classe, de geração ou de etnia. Se, em outras épocas, divindades míticas e religiosas eram invocadas para explicar a natureza e as relações humanas, é a ciência que cumpre, desde a modernidade, a função de buscar explicaçōes e regular a ordem social (Bock, 2003). Cabe destacar que a ciência não é algo abstrato, mas "produto de pessoas concretas, situadas em suas posições de gênero, etnia, geração, classe. Um campo científico não existe a despeito das pessoas que o produzem. Pelo contrário, é tão vivo quanto aqueles que o sustentam e tão dinâmico quanto as trocas e o jogo de forças por elas gerado" (Nuernberg, 2005: 283). Em uma época de inseguranças e de incertezas, características de nosso líquido mundo moderno, em que tudo se move e se desloca (Bauman, 2004), normatizar posições estáticas de gênero parece necessário à manutenção da ordem vigente, regulação à qual podem contribuir alguns discursos veiculados pela ciência. Problematizar lugares sociais, públicos e privados ocupados por homens e por mulheres, tanto quanto desconstruir as certezas em relação às subjetividades, aos corpos e aos desejos (Butler, 2003, 2004; Louro, 1999), torna-se ameaçador à inteligibilidade da estrutura social, organizada sob a forma de prerrogativas e de exclusões inscritas nas relações de poder e de gênero. Teorias androcêntricas e individualistas contribuem para produzir e legitimar crenças no indivíduo como entidade autônoma, abstrata, universal (Bock, Furtado \& Teixeira, 1993) e masculina, perpetuando visões binárias e estáticas entre os sexos/gêneros, como se tais diferenças estivessem situadas "dentro dos indivíduos" (Siqueira, 1997), quase impermeáveis ao questionamento e à modificação. Ao advogar a articulação da clínica à política na prática da terapia feminista da família, implicamo-nos na produção de saberes e de práticas comprometidos em "desvincular a militância da tristeza, pois o desejo pode ser revolucionário” (Deleuze \& Guatarri, 1997: 23).

\section{REFERÊNCIAS BIBLIOGRÁFICAS}

Adelman, M. (2003). Das margens ao centro: refletindo sobre a teoria feminista e a sociologia acadêmica. Estudos Feministas, 11, 1, 284-288.

Andersen, T. (1991). Processos reflexivos. Rio de Janeiro: NOOS.

Andolfi, M. \& Angelo, C. (1989). Tempo e mito em terapia familiar. Porto Alegre: Artes Médicas.

Bauman, Z. (2004). Amor líquido: sobre a fragilidade dos laços humanos. Rio de Janeiro: Jorge Zahar. 
Benhabib, S. \& Cornell, D. (Eds.) (1987). Feminismo como critica da modernidade. Rio de Janeiro: Rosa dos Tempos.

Blay, E. (2001). Oito de Março: conquistas e controvérsias. Estudos Feministas, 9, 2, 601608.

Bock, A. M. B. (2003). A perspectiva sócio-histórica na formação em psicologia. Petrópolis: Vozes.

Bock, A. M. B.; Furtado, O. \& Teixeira, M. (1993). Psicologias: uma introdução ao estudo da psicologia. São Paulo: Saraiva.

Bordo, S. (2001). A feminista como o "outro". Estudos Feministas, 8, 1, 10-29.

Boscolo, L.; Cecchin, G.; Hoffman, L. \& Penn, P. (1993). A terapia familiar sistêmica de Milão. Porto Alegre: Artes Médicas.

Brino, R. F. \& Willians, L. C. A. (2003). Capacitação do educador acerca do abuso sexual infantil. Interação em Psicologia, 7, 2, 1-10.

Burck, C. \& Daniel, G. (1994). Feminismo e terapia estratégica: contradição ou complementação? Em Perelberg, R. J. \& Miller, A. C. (Eds.). Os sexos e o poder nas famílias (pp. 94-115). Rio de Janeiro: Imago.

Butler, J. (2003). Problemas de gênero: feminismo e subversão da identidade. Rio de Janeiro: Civilização Brasileira.

- (2004). Undoing Gender. New York, London: Routledge.

Canevacci, M. (1987). Dialética da família. São Paulo: Brasiliense.

Colling, A. M. (1997). A resistência da mulher à ditadura militar no Brasil. Rio de Janeiro: Rosa dos Tempos.

Costa, A. (1994). Os estudos da mulher no Brasil ou a estratégia da corda bamba. Estudos Feministas, E.N., 401-409.

Costa, C. L. \& Schmidt, S. P. (2004). Feminismo como poética/política. Em Costa, C. L. \& Schmidt, S. P. (Eds.). Poéticas e politicas feministas (pp. 9-18). Florianópolis: Ed. Mulheres.

Costa, L. F; Penso, M. A. \& Féres-Carneiro, T. (1992). Reorganizações familiares: as possibilidades de saúde a partir da separação conjugal. Psicologia: Teoria e Pesquisa, 8, 495-503.

Deleuze, G. \& Guatarri, F. (1997). Mil platôs: capitalismo e esquizofrenia (v. 4). São Paulo: 34.

Diamond, I. \& Quinby, L. (1998). Feminism \& Foucault: reflections on resistance. Disponível em: <http://www.thefoucaultian.ukm>. Acessado em 10/03/2004.

Eichler, M. (1988). Nonsexist Research Methods: a practical guide. Winchester: Allen \& Unwin.

Eiguer, A. (1998). A transmissão do psiquismo entre geraçôes: enfoque em terapia familiar psicanalítica. São Paulo: Unimarco. 
Farah, M. F. (2004). Gênero e políticas públicas. Estudos Feministas, 12, 1, 47-71.

Ferreira, E. X. (1996). Mulheres, militância e memória. Rio de Janeiro: Fundação Getúlio Vargas.

Figueira, S. (1986). Uma nova familia? Rio de Janeiro: Zahar.

Fonseca, T. M. G. (1997). Psicologia e relações de gênero: o gênero da ciência psicológica.

Em Zanella, A. V.; Siqueira, M. J.; Lulhier, L. A. \& Molon, S. I. (Eds.). Psicologia e práticas sociais (pp. 317-321). Porto Alegre: ABRAPSO.

Foucault, M. (1969). A arqueologia do saber. Petrópolis: Vozes.

- (1969). História da sexualidade III: o cuidado de si. Rio de Janeiro: Graal, 1988.

. (1976). O sujeito e o poder. Em Dreyfus, H. \& Rabinow, P. (Eds.). Michel

Foucault: uma trajetória filosófica - além do estruturalismo e da hermenêutica (pp. 231-

249). Rio de Janeiro: Forense, 1995.

. (1975). Vigiar e punir: nascimento da prisão. Petrópolis: Vozes, 2002.

Goldner, V. (1985). Warning: family therapy may be hazardous to your health. The Family Therapy Networker, 9, 6, 18-23.

- (1988). The treatment of violence and victimization in intimate relationships. Family Process, 37, 263-286.

Goodrich, T. J.; Rampage, C.; Ellman, B. \& Halstead, K. (1990). Terapia feminista da familia. Porto Alegre: Artes Médicas.

Harding, S. (1986). The science question in feminism. New York: Cornell University. . (1993). A instabilidade das categorias analíticas na teoria feminista. Estudos Feministas, 1, 1, 7-31.

Hare-Mustin, R. T. (1987). The problem of gender in family therapy theory. Family Process, 26, 15-27.

Jaggar, A. M. (1997). Amor e conhecimento: a emoção na epistemologia feminista. Em Jaggar, A. M. \& Bordo, S. R. (Eds.). Gênero, corpo, conhecimento (pp. 157-185). Rio de Janeiro: Rosa dos Tempos.

Jones, E. (1994). Feminismo e terapia de família: os casamentos complicados podem dar certo? Em Perelberg, R. J. \& Miller, A. C. (Eds.). Os sexos e o poder nas famílias (pp. $75-$ 93). Rio de Janeiro: Imago.

Keller, E. F. (1985). Reflections on gender and science. Connecticut: Yale University.

Louro, G. L. (1999). Pedagogias da sexualidade. Em Louro, G. L. (Ed.). O corpo educado (pp. 7-34). Belo Horizonte: Autêntica.

- (2003). Currículo, gênero e sexualidade: o "normal", o "diferente" e o "excêntrico”. Em Louro, G. L; Neckel, J. F. \& Goellner, S. V. (Eds.). Corpo, gênero e sexualidade: um debate contemporâneo na educação (pp. 41-52). Porto Alegre: Vozes.

Maluf, S. (2004). Os dossiês da REF: além das fronteiras entre academia e militância. Estudos Feministas, 12, N.E., 235-243. 
Millet, K. (1970). Sexual politics. New York: Doubleday \& Company.

Minuchin, S. (1981). Famílias: funcionamento e tratamento. Porto Alegre: Artes Médicas. Narvaz, M. (2005). Submissão e resistência: explodindo o discurso patriarcal da dominação feminina. Tese de Doutorado. Curso de Pós-Graduação em Psicologia do Desenvolvimento, Universidade Federal do Rio Grande do Sul, Porto Alegre, RS.

Narvaz, M. \& Koller, S. H. (2005). A invenção da família. Pensando Famílias, 9, 13-30. . (2006a). A família que não é sagrada: mitos e fatos sobre abuso sexual na família. Em Portela, F. \& Franceschini, I. (Eds.). Família e aprendizagem: uma relação necessária (pp.59-80). Rio de Janeiro: Wak.

(2006b). Famílias e patriarcado: da prescrição normativa à subversão criativa. Psicologia \& Sociedade, 18, 1, 49-56.

- (2006c). Mulheres vítimas de violência doméstica: compreendendo subjetividades assujeitadas. Psico, 37, 7-13.

. (2006d). Metodologias feministas e estudos de gênero: articulando pesquisa, clínica e política. Psicologia em Estudo, Maringá, 11, 3, 647-654.

Negrão, T. (2004). Nós e rupturas da rede de apoio às mulheres. Em Strey, M; de Azambuja, M. P. R. \& Jaeger, F. P. (Eds.). Violência, gênero e políticas públicas (pp. 216-258). Coleção Gênero e Contemporaneidade, v. II. Porto Alegre: Edipucrs.

Neill, J. R. \& Kniskern, D. P. (1990). Da psique ao sistema. Porto Alegre: Artes Médicas.

Neves, S. \& Nogueira, C. (2003). A psicologia feminista e a violência contra as mulheres na intimidade: a (re)construção dos espaços terapêuticos. Psicologia \& Sociedade, 15, 2 , 43-64.

Nogueira, C. (2001). Feminismo e discurso do gênero na psicologia social. Psicologia \& Sociedade, 13, 1, 107-128.

Nuernberg, A. (2005). Gênero no contexto da produção cientifica brasileira. Tese de Doutorado. Programa de Pós-Graduação Interdisciplinar em Ciências Humanas, Centro de Filosofia e Ciências Humanas da Universidade Federal de Santa Catarina, Florianópolis, SC.

Oliveira, F. (2004). A Convenção de Belém do Pará dez anos depois. <http:// cepcos.sites.uol.com.br>. Acessado em 10/12/2004.

Pateman, C. (1993). O contrato sexual. Rio: Paz e Terra.

Penn, P. (1988). Rape flashbacks: constructing a new narrative. Family Process, 37, 299321.

Perelberg, R. J. (1994). Igualdade, assimetria e diversidade: sobre as conceitualizações dos sexos. Em Perelberg, R. J. \& Miller, A. C. (Eds.). Os sexos e o poder nas famílias (pp. 4767). Rio de Janeiro: Imago.

Rampage, C. \& Avis, J. M. (1998). Identidade sexual, feminismo e terapia familiar. Em Elkaim, M. (Ed.). Panorama das terapias familiares (pp. 189-251). São Paulo: Summus. 
Ravazzola, M. C. (1997). Violencia familiar: el abuso relacional como un ataque a los derechos humanos. Sistemas Familiares, 23, 29-42. . (1999). Historias infames: los maltratos en las relaciones. Buenos Aires: Paidós.

Schmidt, S. P. (2004). Como e por que somos feministas. Estudos Feministas, 12, N.E., 1722.

Schnitman, D. F. (1996). Ciência, cultura e subjetividade. Em Schnitman, D. F. (Ed.). Novos paradigmas, cultura e subjetividade (pp. 9-21). Porto Alegre: Artes Médicas.

Siqueira, M. J. T. (1997). A(s) psicologias e a categoria gênero: anotações para discussão. Em Zanella, A. V.; Siqueira, M. J. T.; Lulhier, L. A. \& Molon, S. I. (Eds.). Psicologia e práticas sociais (pp. 271-279). Porto Alegre: ABRAPSO.

Strey, M. N.; Werba, G. C. \& Nora, T. C. (2004). “Outra vez essa mulher?” Processo de atendimento a mulheres em situação de violência nas delegacias da mulher do RS. Em Strey, M. N.; de Azambuja, M. P. R. \& Jaeger, F. P. (Eds.). Violência, gênero e políticas públicas (pp. 101-122). Coleção Gênero e Contemporaneidade, v. II. Porto Alegre: Edipucrs.

Toneli, M. J. (2003). Publicações feministas sediadas em ONGS: limites, alcances e possibilidades. Estudos Feministas, 11, 1, 265-270.

Urry, A. (1994). A luta por uma prática feminista na terapia de família: premissas. Em Perelberg, R. J. \& Miller, A. C. (Eds.). Os sexos e o poder nas famílias (pp.116-130). Rio de Janeiro: Imago.

Vasconcelos, M. J. E. (1995). Terapia Familiar Sistêmica: bases cibernéticas. Campinas: Psy.

\section{NoTAS}

1 Este artigo foi baseado nos estudos de doutorado da primeira autora sob orientação da segunda autora.

Recebido em 11 de abril de 2007 Aceito para publicação em 30 de outubro de 2007 